\title{
The category effect in visual search depends on physical rather than conceptual differences
}

\author{
LESTER E. KRUEGER \\ Ohio State University, Columbus, Ohio
}

\begin{abstract}
Is a target letter (digit) more readily detected in a digit (letter) background because of conceptual-level differences between letters and digits or because of physical-level differences? When letters and digits were matched on physical features, both for the target set and the background set, no letter vs. digit category effect was found. With physical differences eliminated, search was faster and more accurate for letter than for digit targets and distractors, presumably because of the greater familiarity of letters. Presenting the same characters in normal and mirrorreversed orientation, which also minimized featural differences between categories, produced only a small normal vs. reversed category effect. In a normal background, a reversed target lost much more from its unfamiliarity than it gained from mismatching the background. The present results indicate that the category effect vanishes when only conceptual level differences are present.
\end{abstract}

Physical differences can greatly speed letter or digit search (e.g., a $\mathrm{Z}$ is found easily in a field of curved letters), perhaps because they permit target detection to occur at the preattentive level (Neisser, 1967). Higher level, or conceptual, properties of the background also may greatly affect target detection, however. In the category effect, for example, a target letter (digit) is detected more readily in a digit (letter) background (Ingling, 1972; Jonides \& Gleitman, 1972). By minimizing between-category physical differences, the present study tests whether the category effect is a conceptual-level phenomenon.

Whether the category effect is truly conceptual, as its name implies, has important implications for models of early processing. Merikle (1980) found a partial-report advantage over whole report when subjects were cued by category (letters, digits), and he concluded that iconic memory was not precategorical. However, Merikle did not control for structural features that might distinguish letters from digits; for example, "symmetry about some axis is more prevalent among letters than digits; on many type faces, letters tend to be wider than digits" (Jonides \& Gleitman, 1972, p. 457). Digits have a greater balance of linear and curvilinear features than do uppercase letters, of which $58 \%$ contain only linear elements (Keren, 1977; McCarthy, 1976, 1979).

One problem for the featural explanation, though, is that although the name of a shape seemingly should

This study was supported in part by National Institute of Mental Health Grant MH32295. The author is grateful to Lori Collner and Mary Pejeau for assistance in collecting the data and to Jonathan Baron, John Duncan, John M. Flach, Nancy Ingling, John Jonides, Robert Proctor, and Ronald G. Shapiro for useful discussions and comments. Requests for reprints should be sent to Lester E. Krueger, Human Performance Center, Ohio State University, 404-B West 17th Avenue, Columbus, Ohio 43210. not affect its physical distinctiveness in various contexts, Jonides and Gleitman (1972) did find a category effect for the ambiguous target character $O$, depending on whether it was called a "zero" or an "oh" when used with a particular class of background. However, as Gleitman and Jonides (1976) pointed out, if the featural analysis is flexible, and if the character $O$ contains features pertaining to both classes, a person may extract only those features that define the category indicated (i.e., digit for "zero," letter for "oh"). Furthermore, Duncan (1983a) failed to replicate the "oh-zero" phenomenon, finding a category effect only with unambiguous targets. He concluded that the category effect was due entirely to uncontrolled variation in physical resemblance between the target and nontargets.

If fewer features are needed to categorize than to identify uniquely a character, then the perceptual analysis need be less deep in the between-category condition. If the locus of the category effect is at memory comparison rather than encoding (e.g., Deutsch, 1977; Taylor, 1978), however, then the perceptual analysis ought to be just as deep in the betweencategory as in the within-category condition. Using special recognition tests and catch trials, Gleitman and Jonides (1976) found that targets and field items were processed less deeply in between-category search. Similarly, Jonides and Gleitman (1976) found that a category mismatch allowed the subject to locate the target without first identifying all of the distractor items. Butler (1975) found that a backward mask altered the serial position curve on accuracy for withincategory, but not between-category, search, indicating that categorization, but not identification, is accomplished during an initial parallel operation. Thus, there is much support for the featural explanation of the category effect. 
More direct tests of the featural factor also have been made. Although Ingling (1972) equated not only the letter and digit target sets on physical features, but also the letter and digit background sets, she still found a category effect. However, persisting physical differences between her background sets, for example, "the numbers used had more small curved lines than did the letters" (p. 241), might yet have produced the category effect. Keren (1977) went further in equating physical features. He somewhat distorted his characters, so that a letter was nearly identical in its featural properties with its paired digit, and he obtained no category effect on target-absent trials. Duncan (1983b) also paired similar letters and digits, and he found a category effect. However, his effect was based on a partial-report advantage, which may simply have reflected lower output interference on partial (vs. whole) report. By controlling for physical similarity on a single aspect (straight vs. curved characters), Corcoran and Jackson (1977) eliminated the category effect in one case (Experiment III), but not in another (Experiment I). White (1977) controlled for the physical factor by printing each of the six elements in a display in a different typeface or type size, and he obtained no category effect. Staller and Lappin (1979) found that search for consonant targets was just as fast through all-consonant strings as through consonant-vowel strings when the two distractor sets were equated on physical features. Krueger and Hettinger (in press) found no category effect for odd vs. even digits, presumably because the two sets share similar physical features (Levine, 1977).

The present experiments, like Keren's, paired particular letters with physically similar digits, but did not distort the characters (see Figure 1). The present apparatus and type font had produced a category effect when featural differences were not controlled (Krueger \& Hettinger, in press). In the present experiments, both targets and distractors were equated on physical appearance, so that the perceptual process could not be adjusted for physical differences in a particular combination of target and background class. Display size was varied $(2,4,6$ characters) in order to determine whether the RT function on between-category trials had a zero slope, as Jonides and Gleitman (1972) had found on "oh-zero" and other targets.

\section{Orientation Effect}

The present two experiments also tested for a category effect based on normal vs. mirror-reversed character orientation. Mirror-reversed characters differ from normal characters at the conceptual level (i.e., they are not nameable) but not at the physical level (i.e., they have the same basic features as their normal counterparts). Letter orientation is a relatively weak selection cue in partial report (Snyder, 1972; von Wright, 1970), presumably because a change in

\begin{tabular}{|c|c|c|}
\hline & target se & background sef \\
\hline & 56 & 123479 \\
\hline & $S G$ & $\mathrm{~L} Z \mathrm{Z} \mathrm{K} \mathrm{J}$ \\
\hline
\end{tabular}

Figure 1. Letters and digits used as target and background sets in Experiments 1 and 2. The stimuli shown were traced from a photograph taken of the characters on the display screen.

orientation "leaves brightness, size, slant relationships, and other obvious physical variables unchanged" (Snyder, 1972, p. 429).

Letters in unfamiliar orientation typically take longer to compare and to search through than normal letters (e.g., Egeth \& Blecker, 1971; Greenberg \& Krueger, 1983), but their special and distinctive encoding might provide an important advantage in some cases. Frith (1974) found that a mirror-reversed letter was detected more readily in a background of normal letters than was a normal letter in a background of mirror-reversed letters. Reicher, Snyder, and Richards (1976) obtained similar findings, and concluded that "unfamiliar characters retard performance when they are background characters but may help performance when they are target characters" (p. 529), owing to "a mechanism sensitive to the unusual or informative" (p. 530). However, target and background familiarity were confounded in these studies, and it may have been mainly the familiarity of the background letters, not the novelty of the target, that aided performance. To remove this confounding, Experiments 1 and 2 varied target and background orientation orthogonally.

In both experiments, a single target character was specified before each block of trials, thus enabling the subject to become set for a particular target class (letter, digit) and orientation (cf. Gleitman \& Jonides, 1978). The background class and orientation were varied within each block in Experiment 1, but not in Experiment 2, which was run to ensure that the absence of a letter vs. digit category effect in Experiment 1 was not due simply to the intermixing of background types. Keren (1977) found that intermixing within-category and between-category conditions eliminated the category effect, which "suggests that subjects have to tune themselves in order to use the advantage for the between conditions" (p. 17). In other cases, though, intermixing the two display conditions seems not to have mattered (Gleitman \& Jonides, 1978; Jonides \& Gleitman, 1976).

\section{METHOD}

\section{Subjects}

Forty-eight Ohio State University undergraduates (24 in Experiment 1 and 24 in Experiment 2) participated for credit in an introductory psychology course. All subjects had at least 20/30 vision (corrected), as tested with a Snellen chart. 


\section{Apparatus}

Stimuli were presented at a $60-\mathrm{Hz}$ refresh rate and at $32 \mathrm{~cd} / \mathrm{m}^{2}$ intensity on a greenish-tint, fast-decay P31 phosphor (decay to $1 \%$ intensity at $.25 \mathrm{msec}$ after display of fset) by an Imlac PDS-4 graphics computer, which also measured RT to an accuracy of $1 \mathrm{msec}$. The characters, presented as thin, illuminated lines on a dark screen, were software generated and made up of short line vectors so as to resemble normal English uppercase letters and Arabic numerals. Each subject sat alone in a dark room, with his or her head held fast in a chinrest located $70 \mathrm{~cm}$ from the display screen.

\section{Stimulus Materials}

Each character was $.29 \mathrm{~cm}$ wide and $.43 \mathrm{~cm}$ high, and each was located $1.5 \mathrm{~cm}$ from the center fixation mark. Each display contained two, four, or six characters. When six were shown, the characters were evenly spaced (i.e., at $2,4,6,8,10$, and 12 o'clock) on an imaginary circle that was $3.16 \mathrm{deg}$ high and wide. When two or four were shown, the two filled or two missing positions were selected randomly from the set of diametrically opposite pairs, e.g., 2 and 8 o'clock. The displays were filled by random sampling (without replacement) from the set of six background digits or letters. A target character replaced one of the distractors on half of the trials.

As shown in Figure 1, 4 characters were used exclusively as targets $(5,6 ; S, G)$ and 12 were used as distractors $(1,2,3,4,7,9$; $\mathrm{L}, \mathrm{Z}, \mathrm{B}, \mathrm{K}, \mathrm{J}, \mathrm{P})$. The letter and digit members of each set were matched as closely as possible on physical features. The matched pairs were 5,S, and 6,G for the target set, and $1, \mathrm{~L} ; 2, \mathrm{Z} ; 3, \mathrm{~B} ; 4, \mathrm{~K}$; 7,J; and 9,P for the background set.

In Experiment 1, the 16 regular blocks represented two replicas of all combinations of target identity $(5,6, G, S)$ and target orientation (normal vs. left-to-right mirror-reversed) $(2 \times 4 \times 2=16)$. The 24 regular trials in each block represented all combinations of display size (2, 4, 6 characters), target presence vs. absence, background class (letter vs. numeral), and background orientation (normal vs. left-to-right mirror-reversed) $(3 \times 2 \times 2 \times 2=24)$. Four practice trials preceded each block, and there were four practice blocks of 8 trials each, for a total of $\mathbf{4 8 0}$ trials. Four different random orderings of blocks and of trials within blocks were used.

In Experiment 2, the 16 regular blocks represented all combinations of target class, target orientation, background class, and background orientation $(2 \times 2 \times 2 \times 2=16)$. Since not all four targets could be used with every combination of the other block factors, 5 and $S$ were used as targets for half of the subjects and 6 and $G$ were used for the other half. Within each block, the 24 regular trials represented four replicas of all combinations of display size and target presence vs. absence $(4 \times 3 \times 2=24)$.

\section{Procedure}

The subjects were instructed to keep their eyes focused on the center fixation mark at all times and to look for the exact same shape and orientation in the display as specified by the target character shown for $3 \mathrm{sec}$ before the block. The subjects were asked to respond as rapidly as possible, but not at the expense of accuracy. Half of the subjects responded "yes"' (target present) with a left-hand buttonpress and "no" (target absent) with a righthand buttonpress; and the other half had the reverse hand assignment. The display stayed on until the subject responded, after which feedback on the accuracy of the response was shown for $2 \mathrm{sec}$; then the fixation point alone appeared for $.5 \mathrm{sec}$ before the next display. A trial was discarded if the RT was below $200 \mathrm{msec}$ or over $3 \mathrm{sec}$, and mean RT was computed based on correct trials only.

\section{RESULTS}

Intermixing (vs. blocking) background orientation and class made subjects more careful. Judgments were somewhat, though not significantly, slower
$[F(1,46)=2.16]$ in Experiment 1 than in Experiment 2 and were significantly more accurate $[F(1,46)=7.02$, $\mathrm{p}<.025$ ] (see Table 1). The two experiments did not differ otherwise, however, and the results will be presented for the two experiments combined.

\section{Orientation Effect}

As shown in Table 1, normal (vs. reversed) orientation significantly aided performance. Normal targets reduced RT by $65 \mathrm{msec}[\mathrm{F}(1,46)=69.40, \mathrm{p}<.001]$ and errors by $0.58 \%[F(1,46)=5.31, p<.05]$. Normal distractors reduced RT by $84 \mathrm{msec}[\mathrm{F}(1,46)=$ $168.15, \mathrm{p}<.001]$ and errors by $1.31 \%[\mathrm{~F}(1,46)=$ $29.64, p<.001]$

The target orientation $\times$ background orientation interaction was significant on both $\mathrm{RT}[\mathrm{F}(1,46)=$ $4.82, p<.05]$ and errors $[F(1,46)=5.01, p<.05]$. However, a target-background orientation mismatch reduced RT by only $17 \mathrm{msec}$ and errors by $0.55 \%$ (see Table 1). Thus, it never paid to present a mirrorreversed target, because any gain from a mismatch was more than offset by the loss from its unfamiliarity. On normal-background trials analyzed separately, having a normal, that is, matching, target significantly reduced $R T[F(1,46)=22.58, p<.001]$ and slightly, but insignificantly, reduced errors $(F<1)$. The latter RT effect was larger when the target was present rather than absent, 75 vs. $23 \mathrm{msec}[\mathrm{F}(1,46)$ $=43.43, \mathrm{p}<.001]$, but was significant even on the target-absent trials analyzed separately $[F(1,46)=$ $4.67, \mathrm{p}<.05]$.

Background orientation was more important than target orientation. On orientation-mismatch trials analyzed separately, reversing the target rather than the distractors significantly reduced $R T[F(1,46)=$ $5.32, p<.025]$ and errors $[F(1,46)=4.96, p<.05]$. On RT, this effect was restricted to target-absent trials $[F(1,46)=47.13, p<.001]$.

\section{Letter vs. Digit Category Effect}

As shown in Table 2, using letters (vs. digits) significantly aided performance [for targets, $F(1,46)=$

Table 1

Experiments 1 and 2: Mean Response Time (in Milliseconds) and Percent Error Rate by Target Orientation (Normal, Reversed) and Background Orientation

\begin{tabular}{|c|c|c|c|c|}
\hline \multirow{3}{*}{$\begin{array}{l}\text { Background } \\
\text { Orientation }\end{array}$} & \multicolumn{4}{|c|}{ Target Orientation } \\
\hline & \multicolumn{2}{|c|}{ Normal } & \multicolumn{2}{|c|}{ Reversed } \\
\hline & RT & $\mathrm{PE}$ & $\mathrm{RT}$ & PE \\
\hline \multicolumn{5}{|c|}{ Experiment 1} \\
\hline $\begin{array}{l}\text { Normal } \\
\text { Reversed }\end{array}$ & $\begin{array}{l}775 \\
853\end{array}$ & $\begin{array}{l}0.87 \\
1.82\end{array}$ & $\begin{array}{l}832 \\
928\end{array}$ & $\begin{array}{l}1.30 \\
3.08\end{array}$ \\
\hline \multicolumn{5}{|c|}{ Experiment 2} \\
\hline $\begin{array}{l}\text { Normal } \\
\text { Reversed }\end{array}$ & $\begin{array}{l}711 \\
768\end{array}$ & $\begin{array}{l}2.65 \\
3.21\end{array}$ & $\begin{array}{l}752 \\
857\end{array}$ & $\begin{array}{l}2.29 \\
4.21\end{array}$ \\
\hline
\end{tabular}

Note $-R T=$ response time; $P E=$ percent errors. 
Table 2

Experiments 1 and 2: Mean Respone Time (in Milliseconds) and Percent Error Rate by Target Category (Letter, Digit) and Background Category

\begin{tabular}{lcccc}
\hline & \multicolumn{4}{c}{ Target Category } \\
\cline { 2 - 5 } Background & \multicolumn{2}{c}{ Letter } & & Digit \\
\cline { 2 - 5 } Category & $\mathrm{RT}$ & $\mathrm{PE}$ & $\mathrm{RT}$ & $\mathrm{PE}$ \\
\hline & & Experiment 1 & \\
Letter & 791 & 1.09 & 820 & 1.43 \\
Digit & 880 & 2.34 & 897 & 2.21 \\
& & Experiment 2 & & \\
Letter & 715 & 2.18 & 734 & 2.30 \\
Digit & 815 & 3.23 & 823 & 4.64 \\
\hline
\end{tabular}

Note $-R T=$ response time; $P E=$ percent errors.

$7.60, \mathrm{p}<.01$, on $\mathrm{RT}$ and $\mathrm{F}(1,46)=4.59, \mathrm{p}<.05$, on errors; for distractors, $F(1,46)=228.93$, $p<.001$, on RT and $F(1,46)=32.88, p<.001$, on errors]. The better performance on letter distractors seemingly made them less susceptible to orientation effects, because using them significantly reduced the advantage for a normal target, $\mathrm{p}<.05$ or better on both RT and errors, or for a normal background, $p<.001$ on both RT and errors (see Table 3).

What is most striking about the results shown in Table 2, though, is the absence of a letter vs. digit category effect. The target class $\times$ background class interaction was significant neither on $R T[F(1,46)=$ 1.44] nor on errors $(F<1)$. In both experiments, in fact, RT was slightly longer, not shorter, on betweencategory trials. Even when the target and background were both normal, and thus could be categorized most readily as letters or digits, a separate analysis revealed no category effect on either RT or errors ( $F \leqslant 1.30$ in both cases).

Increasing the display size ought to magnify, and thus better reveal, any weak category effect present. As shown in Table 4 (Experiment 1) and Table 5 (Experiment 2), however, the slope of the RT function with increasing display size was no smaller on between-category than within-category trials, and definitely did not approach zero on between-category trials (cf. Jonides \& Gleitman, 1972). Oddly enough, target presence was especially unkind to the category effect, both on RT and errors. On RT, the slower processing of between-category trials was mainly evident when the target was present $[F(1,46)=4.75$, $\mathrm{p}<.05$ ]. On errors, a category mismatch hurt as much when the target was present as it helped when the target was absent $[F(1,46)=7.26, p<.01]$.

In general, increased display size and target absence, which both generally slowed the response, only enhanced effects that were already quite evident in the overall results. Thus, the RT advantage of an orientation mismatch, a letter background, and a normal target or background orientation were greater with increased display size or target absence, and a normal background was especially helpful on large, target-absent displays ( $p<.01$ or better in all cases).

In all cases shown in Tables 4 and 5 , the normaltarget, reversed-background condition had a higher slope, but lower intercept, than the reversed-target, normal-background condition. Thus, the relative importance of target (vs. background) orientation decreased, as one would expect, as display size increased.

\section{DISCUSSION}

When physical differences between sets were largely eliminated in Experiments 1 and 2, there was no advantage whatsoever for a letter-digit contrast, and only a $17-\mathrm{msec}$ advantage for a normal-reversed contrast, which may simply reflect residual physical differences (i.e., orientation-specific features). By contrast, Krueger and Hettinger (in press), using the same apparatus and type font, found a 93-msec letter vs. digit category effect on six-character displays when featural differences were not controlled. Even when the background class was blocked (Experiment 2), so that subjects could prepare for it as well as the target class (cf. Keren, 1977), there was no category effect. Reversed characters may have made it difficult to distinguish digits and letters, but there was no category effect even on blocks in which target and background were both normal. The present results thus provide further evidence that the category effect depends on physical rather than conceptual differences between letters and digits (Duncan, 1983a; Gleitman \& Jonides, 1976; Jonides \& Gleitman, 1976; Keren, 1977; White, 1977).

The conceptual contrast alone may even hurt processing. Some subjects said afterwards that the between-category condition had helped, but others said it had been more difficult because intermixing digits and letters produced "more variety" and made the display "more confusing." Consistent with these

Table 3

Experiments 1 and 2: Mean Response Time (in Milliseconds) and Percent Error Rate by Target Orientation, Background Orientation, and Background Category (Letter, Digit)

\begin{tabular}{llllll}
\hline & \multicolumn{3}{c}{ Background Category } \\
\cline { 2 - 3 } \cline { 5 - 6 } & \multicolumn{2}{c}{ Letter } & & \multicolumn{2}{c}{ Digit } \\
\cline { 2 - 3 } \cline { 5 - 6 } Orientation & RT & PE & & RT & PE \\
\hline Target & & & & \\
Normal & 740 & 1.71 & & 813 & 2.56 \\
Reversed & 790 & 1.79 & & 894 & 3.65 \\
Background & & & & \\
Normal & 736 & 1.48 & & 799 & 2.07 \\
Reversed & 794 & 2.02 & 909 & 4.14 \\
\hline
\end{tabular}

Note-RT = response time; $P E=$ percent errors. 
Table 4

Experiment 1: Mean Response Time (in Milliseconds) and Percent Error Rate by Target-Background Category (Letter, Digit) Match vs. Mismatch, Target and Background Orientation, Target Presence vs. Absence, and Display Size

\begin{tabular}{|c|c|c|c|c|c|c|c|c|}
\hline \multirow{3}{*}{$\begin{array}{l}\text { Target-Background } \\
\text { Orientation }\end{array}$} & \multicolumn{6}{|c|}{ Display Size } & \multirow{2}{*}{\multicolumn{2}{|c|}{$\begin{array}{c}\text { Least-Squares } \\
\text { RT Function }\end{array}$}} \\
\hline & \multicolumn{2}{|c|}{2} & \multicolumn{2}{|c|}{4} & \multicolumn{2}{|c|}{6} & & \\
\hline & $\mathrm{RT}$ & $\mathrm{PE}$ & RT & $\mathrm{PE}$ & $\mathrm{RT}$ & PE & Intercept & Slope \\
\hline \multicolumn{9}{|c|}{ Category Match } \\
\hline \multicolumn{9}{|l|}{ Target Present } \\
\hline Normal-Normal & 647 & 0.52 & 706 & 1.04 & 746 & 0.52 & 601 & 24.75 \\
\hline Reversed-Normal & 740 & 0.52 & 753 & 1.04 & 820 & 1.04 & 691 & 20.00 \\
\hline Normal-Reversed & 680 & 1.04 & 743 & 0.00 & 864 & 2.60 & 578 & 46.00 \\
\hline Reversed-Reversed & 753 & 1.04 & 843 & 1.56 & 893 & 5.21 & 689 & 35.00 \\
\hline \multicolumn{9}{|l|}{ Target Absent } \\
\hline Normal-Normal & 741 & 3.13 & 831 & 0.00 & 963 & 0.00 & 623 & 55.50 \\
\hline Reversed-Normal & 743 & 0.52 & 865 & 3.13 & 1013 & 1.04 & 604 & 67.50 \\
\hline Normal-Reversed & 748 & 2.08 & 930 & 1.04 & 1183 & 2.60 & 519 & 108.75 \\
\hline Reversed-Reversed & 810 & 3.65 & 977 & 1.56 & 1260 & 4.69 & 566 & 112.50 \\
\hline \multicolumn{9}{|c|}{ Category Mismatch } \\
\hline \multicolumn{9}{|l|}{ Target Present } \\
\hline Normal-Normal & 656 & 1.56 & 707 & 0.52 & 774 & 1.04 & 594 & 29.50 \\
\hline Reversed-Normal & 741 & 1.04 & 791 & 2.60 & 908 & 3.13 & 646 & 41.75 \\
\hline Normal-Reversed & 670 & 1.04 & 745 & 2.60 & 867 & 3.13 & 564 & 49.25 \\
\hline Reversed-Reversed & 723 & 1.04 & 870 & 4.17 & 1014 & 8.33 & 578 & 72.75 \\
\hline \multicolumn{9}{|l|}{ Target Absent } \\
\hline Normal-Normal & 722 & 1.04 & 831 & 0.52 & 978 & 0.52 & 588 & 64.00 \\
\hline Reversed-Normal & 754 & 0.52 & 845 & 0.52 & 1007 & 0.52 & 616 & 63.25 \\
\hline Normal-Reversed & 779 & 1.04 & 905 & 3.13 & 1124 & 1.56 & 591 & 86.25 \\
\hline Reversed-Reversed & 779 & 2.08 & 965 & 1.56 & 1243 & 2.08 & 532 & 116.00 \\
\hline
\end{tabular}

Note-RT = response time; $P E=$ percent errors.

Table 5

Experiment 2: Mean Response Time (in Milliseconds) and Percent Error Rate by Target-Background Category (Letter, Digit) Match vs. Mismatch, Target and Background Orientation, Target Presence vs. Absence, and Display Size

\begin{tabular}{|c|c|c|c|c|c|c|c|c|}
\hline \multirow{3}{*}{$\begin{array}{l}\text { Target-Background } \\
\text { Orientation }\end{array}$} & \multicolumn{6}{|c|}{ Display Size } & \multirow{2}{*}{\multicolumn{2}{|c|}{$\begin{array}{l}\text { Least-Squares } \\
\text { RT Function }\end{array}$}} \\
\hline & \multicolumn{2}{|c|}{2} & \multicolumn{2}{|c|}{4} & \multicolumn{2}{|c|}{6} & & \\
\hline & RT & PE & RT & PE & RT & PE & Intercept & Slope \\
\hline \multicolumn{9}{|c|}{ Category Match } \\
\hline \multicolumn{9}{|l|}{ Target Present } \\
\hline Normal-Normal & 626 & 3.13 & 633 & 5.21 & 706 & 1.04 & 575 & 20.00 \\
\hline Reversed-Normal & 675 & 2.60 & 694 & 2.60 & 773 & 4.86 & 616 & 24.50 \\
\hline Normal-Reversed & 647 & 4.17 & 690 & 3.65 & 804 & 4.69 & 557 & 39.25 \\
\hline Reversed-Reversed & 713 & 2.60 & 784 & 8.85 & 898 & 3.12 & 613 & 46.25 \\
\hline \multicolumn{9}{|l|}{ Target Absent } \\
\hline Normal-Normal & 686 & 5.21 & 766 & 0.00 & 870 & 3.12 & 590 & 46.00 \\
\hline Reversed-Normal & 692 & 0.52 & 747 & 2.08 & 878 & 0.52 & 586 & 46.50 \\
\hline Normal-Reversed & 680 & 2.60 & 795 & 4.69 & 943 & 4.69 & 543 & 65.75 \\
\hline Reversed-Reversed & 721 & 3.65 & 928 & 4.34 & 1105 & 3.99 & 534 & 96.00 \\
\hline \multicolumn{9}{|c|}{ Category Mismatch } \\
\hline \multicolumn{9}{|l|}{ Target Present } \\
\hline Normal-Normal & 644 & 2.08 & 637 & 4.17 & 718 & 1.56 & 592 & 18.50 \\
\hline Reversed-Normal & 675 & 1.04 & 735 & 3.65 & 790 & 6.42 & 618 & 28.75 \\
\hline Normal-Reversed & 650 & 2.60 & 703 & 2.08 & 769 & 4.17 & 588 & 29.75 \\
\hline Reversed-Reversed & 716 & 5.21 & 781 & 6.25 & 870 & 5.21 & 635 & 38.50 \\
\hline \multicolumn{9}{|l|}{ Target Absent } \\
\hline Normal-Normal & 657 & 3.12 & 735 & 1.56 & 852 & 1.56 & 553 & 48.75 \\
\hline Reversed-Normal & 691 & 1.04 & 755 & 1.04 & 915 & 1.04 & 563 & 56.00 \\
\hline Normal-Reversed & 725 & 2.08 & 798 & 1.04 & 1011 & 2.08 & 559 & 71.50 \\
\hline Reversed-Reversed & 714 & 2.08 & 912 & 2.60 & 1143 & 2.60 & 494 & 107.25 \\
\hline
\end{tabular}

Note $-R T=\cdot$ response time; $P E=$ percent errors. 
comments, performance on the between-category condition was especially poor, both on RT and errors, when the mismatching target was present, thus introducing variety or heterogeneity of class into the display.

On orientation, a category effect was found, but even so a reversed target did not stand out sufficiently from a normal background to be processed as fast as a normal target in that background. Thus, unfamiliarity hurt even when it could have been (and to a certain extent seemingly was) used as a signal to respond immediately. Consistent with previous work (Frith, 1974; Reicher et al., 1976; Richards \& Reicher, 1978), an unfamiliar target in a familiar background was easier to detect than a familiar target in an unfamiliar background. However, the present results indicate that this effect occurred only because the orientation of the distractors, which occupied most display positions, was more important than that of the target.

Letters were easier to process than digits in Experiments 1 and 2. Ingling (1972) found a similar, though nonsignificant, tendency. Krueger and Hettinger (in press), who did not control for featural differences, found faster search through digit than through letter displays, as did also Lefton and Fisher (1976) and McCarthy $(1976,1979)$. McCarthy attributed the superiority of numerals to their greater balance of linear and curvilinear features. Like Ingling, Experiments 1 and 2 largely eliminated the featural differences between digits and letters, thus providing a fairer test of which class is easier to process at the conceptual level. Since letters are encountered more frequently than digits in everyday life, their superiority in Experiments 1 and 2 and in Ingling's study most likely reflects their greater familiarity (Krueger, 1975).

Since letter search is a physical-level task, conceptuallevel factors can have only a limited role, and their effects may easily be exaggerated, eliminated, or even reversed by controlling variation in physical differences or resemblances (Duncan, 1983a). In the present study, eliminating featural differences eliminated the letter vs. digit category effect, but revealed that letters are processed more easily than digits, presumably because of their greater familiarity. Another conceptual-level familiarity effect obtained here was the better performance on normal vs. reversed characters, which were matched, of course, on all orientation-invariant features. Thus, at least some effects occur at the conceptual level, though the category effect is not one of them.

\section{REFERENCES}

Butler, B. E. (1975). Selective attention and target search with brief visual displays. Quarterly Journal of Experimental Psychology, 27, 467-477.
Corcoran, D. W. J., \& Jackson, A. (1977). Basic processes and strategies in visual search. In S. Dornic (ed.), Attention and performance V (pp. 387-4I1). Hillsdale, $\mathrm{NJ}$ : Erlbaum.

Deutsch, J. A. (1977). On the category effect in visual search. Perception \& Psychophysics, 21, 590-592.

Duncan, J. (1983a). Category effects in visual search: A failure to replicate the "oh-zero" phenomenon. Perception \& Psychophysics, 34, 221-232.

DunCAN, J. (1983b). Perceptual selection based on alphanumeric class: Evidence from partial reports. Perception \& Psychophysics, 33, 533-547.

Egeth, H., \& Blecker, D. (1971). Differential effects of familiarity on judgments of sameness and difference. Perception \& Psychophysics, 9, 321-326.

Frith, U. (1974). A curious effect with reversed letters explained by a theory of schema. Perception \& Psychophysics, 16, 113-116.

Gle itman, H., \& Jonides, J. (1976). The cost of categorization in visual search: Incomplete processing of targets and field items. Perception \& Psychophysics, 20, 281-288.

Gle itman, H., \& Jonides, J. (1978). The effect of set on categorization in visual search. Perception \& Psychophysics, 24, 361-368.

Greenberg, S. N., \& Krueger, L. E. (1983). Effect of letter orientation and sequential redundancy on the speed of letter search. Memory \& Cognition, 11, 181-191.

INGLING, N. W. (1972). Categorization: A mechanism for rapid information processing. Journal of Experimental Psychology, 94, 239-243.

Jonides, J., \& Gleitman, H. (1972). A conceptual category effect in visual search: $\mathrm{O}$ as letter or as digit. Perception \& Psychophysics, 12, 457-460.

Jonides, J., \& Gleitman, H. (1976). The benefit of categorization in visual search: Target location without identification. Perception \& Psychophysics, 20, 289-298.

KEREN, G. (1977, November). Additional considerations of the "category" effect. Paper presented at the meeting of the Psychonomic Society, Washington, DC.

KRUEGER, L. E. (1975). Familiarity effects in visual information processing. Psychological Bulletin, 82, 949-974.

KRUEGer, L. E., \& HetTinger, L. J. (in press). Alphanumerical order and category effects in visual search. Bulletin of the Psychonomic Society.

Lefton, L. A., \& Fisher, D. F. (1976). Information extraction during visual search: A developmental progression. Journal of Experimental Child Psychology, 22, 346-361.

LEviNe, D. M. (1977). Multivariate analysis of the visual information processing of numbers. Journal of Multivariate Behavioral Research, 12, 347-355.

McCAnthy, S. V. (1976). Visual serial search across number and letter sets. Perceptual and Motor Skills, 43, 311-314.

McCarthy, S. V. (1979). College women with differential linguistic-quantitative ability patterns: Performance on two visual serial-search tasks. Perceptual and Motor Skills, 49, 791-794.

MERIKLE, P. M. (1980). Selection from visual persistence by perceptual groups and category membership. Journal of Experimental Psychology: General, 109, 279-295.

Ne isser, U. (1967). Cognitive psychology. New York: AppletonCentury-Crofts.

Reicher, G. M., Snyder, C. R. R., \& Richards, J. T. (1976). Familiarity of background characters in visual scanning. Journal of Experimental Psychology: Human Perception and Performance, 2, 522-530.

Richards, J. T., \& Reicher, G. M. (1978). The effect of background familiarity in visual search: An analysis of underlying factors. Perception \& Psychophysics, 23, 499-505.

SNydE R, C. R. R. (1972). Selection, inspection, and naming in visual search. Journal of Experimental Psychology, 92, 428-431.

Stalle R, J, D., \& LappiN, J. S. (1979). Word and nonword superiority effects in a letter detection task. Perception \& Psychophysics, $25,47-54$. 
TAYLOR, D. A. (1978). Identification and categorization of letters and digits. Journal of Experimental Psychology: Human Perception \& Performance, 4, 423-439.

von Wright, J. M. (1970). On selection in visual immediate memory. In A. F. Sanders (Ed.), Attention and performance III (pp. 280-292). Amsterdam: North-Holland. (Reprinted from Acta Psychologica, 1970, 33, 280-292.)
Wн ITE, M. J. (1977). Identification and categorization in visual search. Memory \& Cognition. 5, 648-657.

(Manuscript received April 23, 1984; accepted for publication April 24, 1984.) 